\title{
Topoisomerase II $\alpha$ Expression in Breast Cancer: Correlation with Outcome Variables
}

\author{
Peter L. Depowski, M.D., Seth I. Rosenthal, M.D., Thomas P. Brien, M.D., Scott Stylos, M.D.,
} Rebecca L. Johnson, M.D., Jeffrey S. Ross, M.D.

Department of Pathology, Albany Medical College (PLD, SIR, TPB, JSR), Albany, New York, and Berkshire Medical Center (SS, RLJ), Pittsfield, Massachusetts

Topoisomerase II $\alpha$ (topo II $\alpha$ ) plays a key role in DNA replication and is a target for multiple chemotherapeutic agents. In breast cancer, topo II expression has been linked to cell proliferation and HER2/ neu protein overexpression. However, its relationship with outcome variables is not well established.

Formalin-fixed, paraffin-embedded primary breast cancers from 184 women (mean age, 60 years) were stained for topo II by automated immunohistochemistry. A topo II expression index (TI) was determined by counting the number of positive cells per high-power field and calculating an overall mean number of positive cells per high-power field. Tumors with a TI of more than 1 were considered positive, and those with a TI of 1 or less were considered negative. A cell proliferation index was determined by automated immunohistochemistry using the MIB-1 antibody in an identical technique. HER-2/neu gene amplification (HER-2 amp) was determined by automated fluorescence in situ hybridization using the Ventana unique sequence probe.

Fifty-nine (32\%) of the tumors had a TI greater than 1. On univariate analysis, increased topo II expression correlated with decreased patient survival $(p=.001)$, advanced tumor stage $(p=.034)$, lymph node metastasis $(p=.018)$, and HER-2 amp $(p=.016)$. Tumor stage $(p<.0001)$, node-positive status $(p<.0001)$, tumor grade $(p=.025)$, HER-2 amp $(p<.0001)$, and MIB-1 overexpression $(p=$ .002) also correlated with survival on univariate analysis. Topo II expression did not correlate with tumor size, grade, estrogen receptor/progesterone receptor status, or disease recurrence. On multivar-

Copyright (C) 2000 by The United States and Canadian Academy of Pathology, Inc.

VOL. 13, NO. 5, P. 542, 2000 Printed in the U.S.A.

Date of acceptance: October 26, 1999.

Address reprint requests to: Jeffrey S. Ross, M.D., Department of Pathology, Mail Code 81, Albany Medical College, 47 New Scotland Avenue, Albany, NY 12208. e-mail: jeffrey_ross@ccgateway.amc.edu; fax: 518-2628092. iate analysis, stage $(p<.0001)$, lymph node metastasis $(p<.0001)$, and tumor grade $(p=.002)$ all independently predicted disease-related death.

Increased topo II expression is associated with an aggressive form of breast cancer featuring HER-2 amp and predicts disease-related death, lymph node metastasis, and advanced tumor stage.

KEY WORDS: Breast cancer, HER-2/neu, MIB-1, Stage, Survival, Topoisomerase II $\alpha$

Mod Pathol 2000;13(5):542-547

Topoisomerase II $\alpha$ (topo II $\alpha$ ) is a component of the DNA machinery that is intricately involved at many levels of DNA metabolism (1-3). Its primary function is to alter DNA topology from its storage (supercoiled) form to a more exposed (partially uncoiled) form by inducing single-strand DNA breaks and simultaneously passing another intact double helix through the gap (4-5).

The anthracycline class of antitumor cytotoxic drugs is topoisomerase poisons specifically targeting topo II $\alpha(2,6-7)$. These drugs create a cleavable complex including drug, topo II $\alpha$, and DNA strand. It is hypothesized that the cleavable complex damages the DNA, causing toxicity, and may induce apoptosis in proliferating tumor cells (8-10). From most in vitro analyses, it has been shown that low levels of topo II $\alpha$ expression in cancer cells are associated with drug resistance, whereas high levels indicate sensitivity (11-13). However, in one study, no correlation between the level of topo II $\alpha$ expression and drug sensitivity in breast cancer cell lines was found (14), and recent reports using paraffinembedded breast cancer tissues failed to find associations between topo II $\alpha$ expression and drug sensitivity (15).

Exclusive of topo II $\alpha$ 's potential role as a target for anticancer drugs, few studies have analyzed it as a potential prognostic marker in breast cancer. Of the limited data available, a common finding has been correlation with known proliferation markers such as MIB-1 immunostaining and tumor S phase 
fraction (16-18). These findings support the role of topo II $\alpha$ as a proliferation marker in breast cancer. An additional finding in some studies has been coexpression of both topo II $\alpha$ and HER-2/neu oncoprotein, a known poor prognostic indicator (1924). Of the few studies that evaluated this association, two recent studies of 230 and 55 breast cancers, respectively, reported significant correlation between HER-2/neu oncoprotein overexpression in tumors with increased topo II $\alpha$ expression. However, in a relatively small study of 30 breast cancers by Lynch et al. (15), no association between HER-2/neu oncoprotein overexpression and a high topo II $\alpha$ index was identified.

The correlation of topo II $\alpha$ expression with other known outcome variables in breast cancer has been inconsistent. Studies have shown a significant correlation of topo II $\alpha$ expression with lymph node metastases, tumor grade, tumor size, and distant metastases (25) and with negative hormone receptor status, high grade, and DNA aneuploidy $(16,18)$. Other studies have found the association of topo II $\alpha$ expression with cell proliferation markers only (15, 17).

In the following study of 184 primary breast cancers, topo II $\alpha$ expression was compared with tumor stage, lymph node metastases, tumor grade, tumor size, estrogen receptor (ER) status, progesterone receptor (PR) status, disease recurrence, survival, HER-2/neu gene status, and MIB-1 expression by univariate and multivariate analysis.

\section{MATERIALS AND METHODS}

\section{Patients}

The clinical records and tissue blocks were obtained from 160 randomly selected patients who underwent either mastectomy or local excision for infiltrating ductal carcinoma at the Albany Medical Center between 1980 and 1985. The clinical records and tissue blocks were also obtained from 24 patients who underwent mastectomy for infiltrating ductal carcinoma at the Berkshire Medical Center between 1980 and 1982. The tumors were staged pathologically according to American Joint Committee on Cancer criteria using the TNM classification scheme. There were 55 (30\%) Stage 1, 90 (50\%) Stage 2, 15 (8\%) Stage 3, and 21 (12\%) Stage 4 cases; 3 tumors were not staged because of lack of avail- able data on tumor size. Hematoxylin and eosinstained slides from each case were reviewed, and the tumors were graded according to the modified Bloom Richardson grading system (26). The tumors were separated into high grade (scores of 8 or 9) and non-high grade (scores of $<8$ ). There were 95 (52\%) lymph node-negative and 89 (48\%) lymph node-positive cases. A total of 117 patients had available ER status data, and 101 patients had available PR status data. There were 107 cases with available HER-2/neu gene amplification (HER-2 amp) data. All 184 patients were included in the survival analysis.

\section{Immunohistochemistry}

Immunohistochemical staining for topo II was performed on the Ventana ES automated immunohistochemistry (IHC) instrument (Ventana Medical Systems, Inc., Tucson, AZ) with an indirect biotin avidin system on $5 \mu \mathrm{m}$ formalin-fixed, paraffinembedded sections from a representative block in each case. Tissue blocks were stored in ambient conditions in the pathology departments of both institutions for 3 to 18 years before IHC procedures. All blocks were cut immediately before IHC. The antigenic determinant sites were unmasked with $0.01 \mathrm{M}$ sodium citrate solution in association with microwave irradiation at maximum power for 15 min for each antibody (27). The slides were subsequently incubated with a biotinylated universal secondary antibody and in avidin peroxidase label (Ventana). After the development of color with diaminobenzidine substrate, the slides were counterstained with hematoxylin. Positive control slides using non-neoplastic human tonsil were included with every batch. To confirm the specificity of the primary antibody, negative control slides were run using an isotype-matched mouse $\operatorname{IgG}_{1}$, (Sigma, St. Louis, MO) at the same concentration as that of the primary antibody. The immunochemicals, incubation times, positive control specimens, and final antibody concentration/dilutions are summarized in Table 1.

\section{Staining Interpretation}

Assessment of topo II staining was performed without prior knowledge of patient clinical pathologic parameters. The staining was uniformly dis-

TABLE 1. Immunohistochemical Primary Antibodies

\begin{tabular}{|c|c|c|c|c|c|}
\hline Antibody & Source & Clone & $\begin{array}{l}\text { Positive Control } \\
\text { Specimens }\end{array}$ & $\begin{array}{l}\text { Final Antibody } \\
\text { Concentration }\end{array}$ & $\begin{array}{l}\text { Primary Antibody } \\
\text { Incubation }\end{array}$ \\
\hline $\begin{array}{l}\text { Monoclonal Antihuman Topo } \\
\text { II } \alpha \text {, IgG }\end{array}$ & $\begin{array}{l}\text { Novocastra Laboratories, Ltd., } \\
\text { Newcastle, UK }\end{array}$ & $3 \mathrm{~F} 6$ & $\begin{array}{l}\text { Non-neoplastic } \\
\text { human tonsil }\end{array}$ & Diluted 1:20 & $32 \min @ 41^{\circ} \mathrm{C}$ \\
\hline $\begin{array}{l}\text { Monoclonal Antihuman MIB- } \\
\text { 1, mouse IgG }\end{array}$ & $\begin{array}{l}\text { Ventana Medical Systems, } \\
\text { Tucson, AZ }\end{array}$ & MM1 & $\begin{array}{l}\text { Non-neoplastic } \\
\text { human tonsil }\end{array}$ & $8 \mu \mathrm{g} / \mathrm{mL}$ & $32 \min @ 41^{\circ} \mathrm{C}$ \\
\hline
\end{tabular}


tributed within the nuclei. No cytoplasmic or membrane staining was observed. A topo II $\alpha$ staining index (TI) was established by visual quantitation at $400 \times$ magnification (surface area of $0.2 \mathrm{~mm}^{2}$ ). Briefly, the index was determined by counting the number of positive cells per high-power field (HPF: field diameter, $0.50 \mathrm{~mm}$, area, $0.20 \mathrm{~mm}^{2}$ ). An overall mean number of positive cells per HPF was calculated. Tumors with a TI of more than 1 (increased expression) were considered positive, whereas those with a TI of 1 or less were considered negative. Only lesional tissue was included in the calculation, and in each case the entire lesion was counted for topo II-positive cells. A similar scoring system was used to create a cell proliferation index by assessment of MIB-1 expression.

\section{Fluorescence In Situ Hybridization}

Unstained 4 - $\mu$-thick formalin-fixed paraffinembedded tissue sections were applied to Plus (Fisher Scientific, Pittsburgh, PA) slides and processed using the Oncor Chromosome In-situ Hybridization system (Oncor, Inc., Gaithersburg, MD) on the Ventana Gen ${ }^{\mathrm{II}}$ automated hybridization instrument. After deparaffinization in xylene and transfer through two changes of $100 \%$ ethanol and being rinsed, slides were placed on the Gen ${ }^{\mathrm{II}}$ instrument. The slides were then incubated for $30 \mathrm{~min}$ in $30 \%$ Oncor pretreatment solution at $45^{\circ} \mathrm{C}$ followed by $45 \mathrm{~min}$ in Oncor digesting solution at $45^{\circ} \mathrm{C}$. Oncor unique sequence digoxigenin-labeled HER2/neu DNA probe was prewarmed for $5 \mathrm{~min}$ at $37^{\circ}$ $\mathrm{C}$ before manual application. The amount of probe hybridization mixture was approximated according to the target area ( $10 \mu \mathrm{L}$ probe mixture per $22 \times 22$ $\mathrm{mm}$ tissue area). Denaturation was accomplished at $69^{\circ} \mathrm{C}$ for $5 \mathrm{~min}$ before slides were incubated overnight at $37^{\circ} \mathrm{C}$. After overnight hybridization and three posthybridization stringency washes, fluorescein-labeled antidigoxigenin detection reagent was manually applied for $28 \mathrm{~min}$ at $37^{\circ} \mathrm{C}$. After removal of the slides from the instrument, each was counterstained with $18 \mu \mathrm{L}$ of propidium iodide antifade (1:2) and covered with a glass coverslip. Slides were evaluated for HER-2/neu gene copy number using a Zeiss Axioskop 50 (Carl Zeiss, Thornwood, NY) fluorescence microscope.

\section{Scoring of Amplification}

The probe displays a single fluorescent signal at the location of each HER-2/neu gene copy. The expectant number of signals in an unamplified tumor cell ranges from 2 to 4 depending on the phase of the cell cycle. Gene copy levels were assessed in at least two sets of 20 nonoverlapping nuclei in each specimen. Tumors were considered amplified for the HER-2/neu gene when a group of 20 cells featuring a mean of five or more signals per cell could be identified $(24,28)$.

\section{Statistical Analysis}

Statistical comparisons were carried out with the STATA software (Computing Resource Center, Santa Monica, CA) using the $\chi^{2}$ test to determine the significance of the association between different variables. The correlation of topo II expression, HER-2 amp by fluorescence in situ hybridization, tumor stage, node-positive status, tumor grade, tumor size, and ER/PR status with each other and disease-related death was performed by univariate analysis and multivariate analysis using the Cox proportional hazards model and the Kaplan Meier test. The level of significance was set at 0.05 .

\section{RESULTS}

The 184 patients ranged in age from 26 to 89 years with a mean age of 60 years. The mean follow-up was 61 months (range, 1 to 164 months). Fifty-five (30\%) were pathologic Stage 1, 90 (50\%)

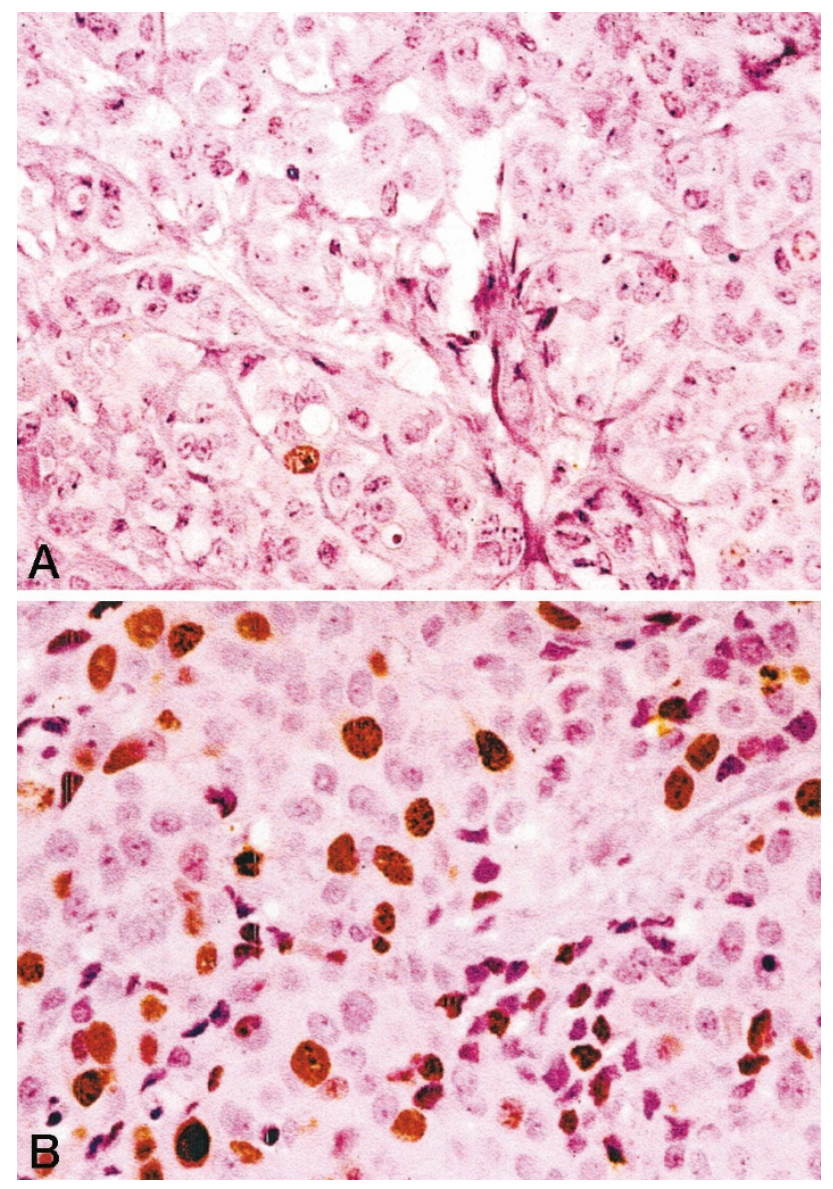

FIGURE 1. A, tumor with topo II expression index of less than 1 and rare positive cell per high-power field $(400 \times)$. B, tumor with topo II expression index of more than 1 and numerous positive cells per highpower field $(400 \times)$. 

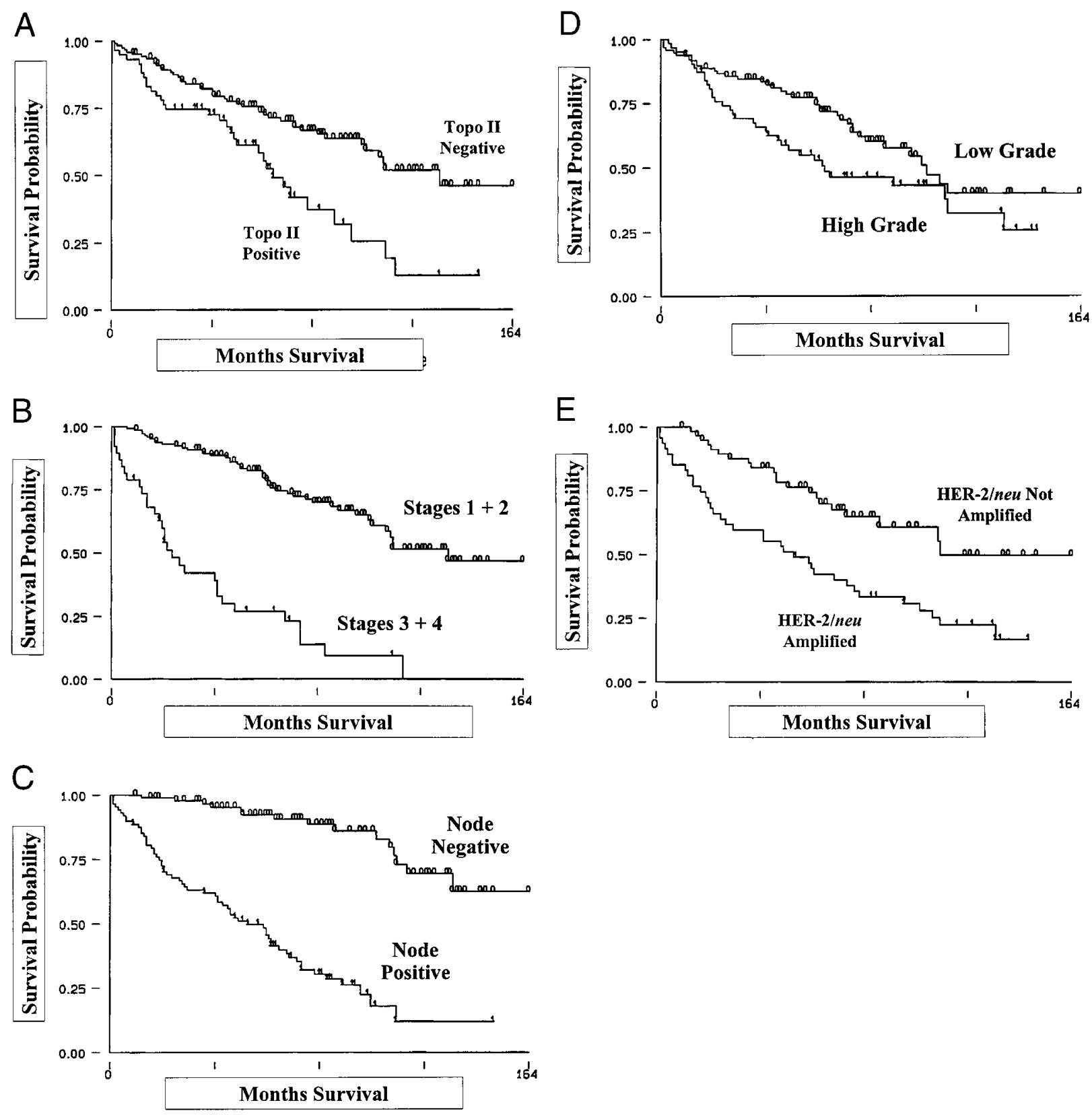

FIGURE 2. A, topo II $\alpha$ expression versus survival. B, stage versus survival. C, node status versus survival. D, tumor grade versus survival. E, HER-2/ neu amp versus survival.

were Stage 2, $15(8 \%)$ were Stage 3, and $21(12 \%)$ were Stage 4 . Eighty-nine $(48 \%)$ patients had axillary node metastases at the time of diagnosis, and 95 patients $(52 \%)$ were node negative. At the time of the study, 42 patients (23\%) had disease recurrence (27 with biopsy-proven recurrence, 15 with radiographic evidence of recurrence), whereas $140(77 \%)$ were disease free. Recurrence data were not available on two patients. Seventy-seven patients $(42 \%)$ had died, and 107 (58\%) were alive at the time of the study. Of the 163 tumors graded, there were 64 (39\%) high-grade tumors and 99 (61\%) non-high grade tumors. Of the 117 patients with available ER data, $82(70 \%)$ were ER positive and $35(30 \%)$ were
ER negative. Of the 101 patients with available PR data, 62 (61\%) were PR positive and 39 (39\%) were PR negative. Forty-eight of 107 patients (45\%) with HER-2 amp data were HER-2/neu gene amplified, whereas $59(55 \%)$ were unamplified.

\section{Topo II Expression by IHC}

Fifty-nine of the 184 breast cancers (32\%) had a TI of more than 1 (mean, 7.6; range, 1.1 to 103) (Fig. 1). There were $125(68 \%)$ cases with TI of 1 or less (mean, 0.2; range, 0 to 1 ). On univariate analysis, increased topo II expression significantly correlated with decreased patient survival ( $p=.001)$ (Fig. 2). 
TABLE 2. Increased Topo Il $\alpha$ Expression and Relation to Clinicopathologic Variables

\begin{tabular}{lll}
\hline \multirow{2}{*}{ Variables } & \multicolumn{2}{c}{ Topo II Index $>1$} \\
\cline { 2 - 3 } & \# Cases & \multicolumn{1}{c}{$P$ value } \\
\hline Disease-related death & $32(42 \%)$ & 0.001 \\
Disease recurrence & $13(31 \%)$ & 0.817 (NS) \\
High stage & $11(52 \%)$ & 0.034 \\
Lymph node metastases & $36(40 \%)$ & 0.018 \\
High tumor grade & $19(30 \%)$ & 0.313 (NS) \\
Tumor size $>2 \mathrm{~cm}$ & $11(21 \%)$ & 0.249 (NS) \\
ER negative & $12(34 \%)$ & 0.886 (NS) \\
PR negative & $13(33 \%)$ & 0.701 (NS) \\
HER-2/neu amplified & $17(35 \%)$ & 0.016 \\
MIB-1 overexpression & $23(35 \%)$ & 0.004 \\
\hline
\end{tabular}

ER, estrogen receptor; PR, progesterone receptor; NS, not significant. $a$ Stage 4 disease.

Of Stage 4 tumors, 11 (52\%) had topo II expression $(p=.034)$. When topo II expression was analyzed stage for stage, the association reached near significance $(p=.085)$. Thirty-six of 89 patients $(40 \%)$ with lymph node metastases had topo II expression $(p=.018)$. Of the 48 tumors with HER-2 amp, 17 (35\%) had a TI of more than $1(p=.016)$. No correlation was seen with topo II expression and tumor size, tumor grade, ER status, PR status, or disease recurrence (Table 2).

\section{Survival Analysis}

On univariate analysis, increased topo II expression $(p=.001)$, tumor stage $(p<.0001)$, nodepositive status $(p<.0001)$, tumor grade $(p=.025)$, HER-2 amp ( $p<.0001)$, and MIB-1 overexpression $(p=.002)$ all correlated with disease-related death (Fig. 2). Tumor size, ER status, and PR status did not correlate with survival. On multivariate analysis, tumor stage $(p<.0001)$, lymph node metastasis $(p<.0001)$, and tumor grade $(p=.002)$ all independently predicted disease-related death.

\section{DISCUSSION}

We evaluated primary breast cancers for topo II $\alpha$ expression and found significant association of increased expression with known outcome variables. Of the few studies that have examined this association, most support our findings $(15-18,25)$. This may indicate a potential role of topo II $\alpha$ as a prognostic marker in breast cancer. Furthermore, a relatively consistent finding in most of these studies and the present study is significant correlation of topo II $\alpha$ with known cell proliferation marker MIB-1. This finding is intuitive in topo II $\alpha$ 's functional role in DNA synthesis and promotes the theory that topo II $\alpha$ is a marker of cell proliferation in breast cancer.

An important prognostic and potentially therapeutic finding is the association of topo II $\alpha$ expres- sion with HER-2/neu oncoprotein overexpression. Of the limited reports that evaluated this comparison, most found significant correlation between the two markers, including the present study $(16,19-$ $20,29)$. This suggests that topo II $\alpha$ is preferentially expressed in a more aggressive subset of breast tumors (HER-2/neu overexpressed). In addition, studies of drug sensitivities imply tumor sensitivity to anthracycline-based therapies from breast cancers with HER-2/neu overexpression $(30,31)$. The basis for this observation may relate to the above association. From this finding, the therapeutic potential with the recent approval of Herceptin (Genentech, Inc., South San Francisco, CA) as an adjuvant therapy in breast cancer is encouraging. Identification of a specific subset of patients who have breast tumors with topo II $\alpha$ expression and coexpression of HER-2/neu offers two specific therapies directed against two specific cancer cell molecular targets. This may result in greater inhibition of cell proliferation and deter disease progression. Moreover, inherent in the secondary toxicity of chemotherapeutic agents (e.g., acute leukemia, myelodysplastic syndrome), not exclusive of the anthracycline class of drugs, the ability for patient selectivity is critical for maximum response and minimal morbidity. Despite this possibility, literature investigating topo II $\alpha$ 's predictive ability in determining response to anthracycline-based therapy is not in complete agreement. In vitro analysis of drug sensitivity and resistance in breast cancer cell lines as predicted by topo II $\alpha$ expression indicates resistance with low levels and sensitivity with high levels (11-13). More recent in vivo studies are not conclusive and have not supported the previously mentioned studies. One study by Jarvinen et al. (18) evaluated response of epirubicin chemotherapy, an anthracycline drug, in advanced breast cancer and correlation with topo II $\alpha$ expression. They found no apparent association. The study population was small (55 patients), but they suggested that clinical epirubicin effect may be mediated through topo II $\alpha$ independent mechanisms. Unfortunately, it is clear that many interactions that control/induce cell growth and transformation are occurring at the cellular level. Our understanding of these processes is limited, and a linear analogy of drug interaction with a single tumor cell target resulting in tumor response may not occur in vivo.

In conclusion, the present study has shown significant correlation of increased topo II $\alpha$ expression with known outcome variables in breast cancer, indicating its potential role as a prognostic marker in these patients. We also reported a subset of tumors with concurrent topo II $\alpha$ expression and HER$2 /$ neu oncogene amplification, which may have therapeutic implications. Further study is war- 
ranted to define better the role of topo II $\alpha$ in disease progression and therapy response.

\section{REFERENCES}

1. Tan KB, Dorman TE, Falls KM, Chung TDY, Mirabelli CK, Crooke ST, et al. Topoisomerase II alpha and topoisomerase II beta differentially spliced forms of topoisomerase II alpha mRNA. Nucl Acids Res 1993;21:3719-23.

2. Withoff S, De Jong S, De Vries EGE, Mulder NH. Human DNA topoisomerase II: biochemistry and role in chemotherapy resistance. Anticancer Res 1996;16:1867-80.

3. Chung DU, Drake SH, Tan KB, Per SR, Crooke ST, Mirabelli CK. Characterization and immunological identification of cDNA clones encoding to human topoisomerase isozymes. Proc Natl Acad Sci U S A 1989;86(23):9431-5.

4. Roca J, Wang JC. DNA transport by a type II DNA topoisomerase: evidence in favor of a two-gate mechanism. Cell 1994; 77:609-16.

5. Osheroff N. Biochemical basis for the interactions of type I and type II topoisomerase with DNA. Pharmacol Ther 1989; 41:223-41.

6. Aisner J, Doyle A, Egorin MJ. Topoisomerase inhibitors conference. University of Maryland Cancer Center, Monterey, California, USA. Cancer Chemother Pharmacol 1994; 34(Suppl):1-134.

7. Pommier Y, Leteurte F, Fesen MR, Fujimori A, Bertrand R, Solary E, et al. Cellular determinants of sensitivity and resistance to DNA topoisomerase inhibitors. Cancer Invest 1994; $12: 530-42$.

8. Lowe SW, Ruley HE, Jacks T, Housman DE. P53-dependent apoptosis modulates the cytotoxicity of anticancer agents. Cell 1993;74:957-67.

9. Liu LF. DNA topoisomerase poisons as anti-tumor drugs. Ann Rev Biochem 1989;58:351-75.

10. D’Arpa P, Liu LF. Topoisomerase-targeting antitumor drugs. Biochem Biophys Acta 1989;989:163-77.

11. Asano T, An T, Zwelling LA, Takano H, Fojo AT, Kleinerman ES. Transfection of a human topoisomerase II alpha gene into etoposide-resistant human breast tumor cells sensitizes the cells to etoposide. Oncol Res 1996;8(3):101-10.

12. Sharma R, Arnold L, Gulliya KS. Correlation between DNA topoisomerase II activity and cytotoxicity and pMC540 and merodantoin sensitive and resistant human breast cancer cells. Anticancer Res 1995;15(2):295-304.

13. Houlbrook S, Addison CM, Davies SL, Carmichael J, Stratford IJ, Harris AL, et al. Relationship between expression of topoisomerase II isoforms and intrinsic sensitivity to topoisomerase II inhibitors in breast cancer cell lines. Br J Cancer 1995;72(6):1454-61.

14. Davis PL, Shaiu WL, Scott GL, Iglehart JD, Hsieh TS, Marks JR. Complex response of breast epithelial cell lines to topoisomerase inhibitors. Anticancer Res 1998;18:2919-32.

15. Lynch BJ, Guinee DG, Holden JA. Human DNA topoisomerase II alpha: a new marker of cell proliferation in invasive breast cancer. Hum Pathol 1997;28(10):1180-8.

16. Jarvinen TA, Kononen J, Pelto-Huikko M, Isola JJ. Expression of topoisomerase II alpha is associated with rapid cell proliferation, aneuploidy and c-erbB2 overexpression in breast cancer. Am J Pathol 1996;148(6):2073-82.

17. Sandri MI, Hochhauser D, Ayton P, Camplejohn RC, White- house R, Turley H, et al. Differential expression of the topoisomerase II alpha and beta genes in human breast cancers. Br J Cancer 1996;73(12):1518-24.

18. Jarvinen TA, Holli K, Kuukasjarvi T, Isola JJ. Predictive value of topoisomerase II alpha and other prognostic factors for epirubicin chemotherapy in advanced breast cancer. $\mathrm{Br}$ J Cancer 1998;77(12):2267-73.

19. Smith K, Houlbrook S, Greenall M, Carmichael J, Harris AL. Topoisomerase II alpha co-amplification with c-erbB2 in human primary breast cancer and breast cancer cell lines: relationship to m-AMSA and mitoxantrone sensitivity. Breast Oncogene 1993;8:933-8.

20. Coutts J, Plumb JA, Brown R, Keith WN. Expression of topoisomerase II alpha and beta in an adenocarcinoma cell line carrying amplified topoisomerase II alpha and retinoic acid receptor alpha genes. Br J Cancer 1993;68(4):793-800.

21. Maguire HC Jr, Greene MI. The neu (c-erbB2) oncogene. Semin Oncol 1989;16:148-55.

22. Slamon DJ, Clark GM, Wong SG, Levin WJ, Ullrich A, McGuire WL. Human breast cancer: correlation of relapse and survival with amplification of the HER-2/neu Oncogene. Science 1987;235:177-82.

23. Toikkanen S, Helin H, Isola J, Joensuu H. Prognostic significance of HER-2/neu oncoprotein in breast cancer: a 30 year follow-up. J Clin Oncol 1992;10:1044-8.

24. Depowski PL, Brien TP, Sheehan CE, Stylos S, Johnson RL, Ross JS. Prognostic significance of p34 ${ }^{\text {cdc2 }}$ cyclin dependent kinase and MIB1 overexpression and HER-2/neu gene amplification detected by fluorescence in situ hybridization in breast cancer. Am J Clin Pathol 1999;112:459-69.

25. Hellemans P, van Dam PA, Geyskens M, van Oosterom AT, Buytaert PH, Van Marck E. Immunohistochemical study of topoisomerase II alpha expression in primary ductal carcinoma of the breast. J Clin Pathol 1995;48:147-50.

26. Elston CW, Ellis IO. Pathologic prognostic factors in breast cancer. The value of histologic grade in breast cancer: experience from a large study with long term follow-up. Histopathology 1991;19:403-10.

27. Shi SR, Key ME, Kalra KL. Antigen retrieval in formalin-fixed, paraffin embedded tissues: an enhancement method for immunohistochemical staining based on microwave oven heating of tissue sections. J Histochem Cytochem 1991;39: 741-8.

28. Press MF, Bernstein L, Thomas PA, Meisner LF, Zhou JY, Ma Y, et al. HER-2/neu gene amplification characterized by fluorescence in situ hybridization: poor prognosis in nodenegative breast carcinomas. J Clin Oncol 1997;15(8):2894904 .

29. Keith WN, Douglas F, Wishart GC, McCallum HM, George $\mathrm{WD}$, Kaye SB, et al. Co-amplification of erbB2, topoisomerase II alpha and retinoic acid receptor alpha genes in breast cancer and allelic loss at topoisomerase I on chromosome 20. Eur J Cancer 1993;29A(10):1469-75.

30. Muss HB, Thor AD, Berry DA, Kute T, Liu ET, Koerner F, et al. C-erbB-2 expression and response to adjuvant therapy in women with node-positive early breast cancer. N Engl J Med 1994;330(18):1260-6.

31. Allred DC, Clark GM, Tandon AK, Molina R, Tormey DC, Osborne CK, et al. HER-2/neu in node-negative breast cancer: prognostic significance of overexpression influenced by the presence of in situ carcinoma. J Clin Oncol 1992;10(4): 599-605. 